\title{
Quality Costing Technique: An Appropriate Financial Indicator for Reducing Costs and Improving Quality in the Organizations
}

\author{
Behnam Neyestani \\ Department of Civil Engineering, De La Salle University, Manila, Philippines \\ behnam neyestani@dlsu.edu.ph
}

\begin{abstract}
Quality costing method is one of the total quality management (TQM) tools. This technique is also the most significant financial performance indicator, which can assist the companies to monitor and control their expenses related the quality of products and services during production process, in order to ensure that the firm is able to satisfy the requirements of the customers. Accordingly, the adoption of this method can cause that the companies save money and being more competitive in the market. However, the main purpose of this paper was to explore and discuss regarding the aspects of this TQM tool, and how it can detect unnecessary costs and maintain good quality for products and services with an aim to attain highest level of customer satisfaction in the organizations.
\end{abstract}

Keywords: Appraisal Costs, Control Costs, Failure Costs, Quality Costing Technique, Quality Costs, and Prevention Costs.

\section{INTRODUCTION}

With the turn of the new millennium, global competition has increased [13]. This competitive pressure motivates the companies' management to verify their "business strategies and practices. One of the key elements of the competitiveness is "quality" as the results of organizational performance [9]. The reason quality has increasingly considered during the last decade is that the companies understood the high cost of poor quality because of its dramatic cost implications and effects on all organizational aspects. Poor quality costs happen, which cause to dissatisfied customers, reduced market

Neyestani B. (2017, March). "Quality Costing Technique: An Appropriate Financial Indicator for Reducing Costs and Improving Quality in the Organizations." https://doi.org/10.5281/zenodo.375973 
share, and even lost business [6]. Thus, producing high quality products and services that fulfill customer needs and expectations is very essential in firms.

Accordingly, the implementation of quality management programs such as TQM has a significant role to improve quality and produce products and services with high quality level. Total quality management (TQM) is a set of opinions and ideas that widely called "management philosophy" [10], which "emphasizes on non-stop quality improvement within all aspects of the organizations" [9, p. 1581]. Oakland [14] stated Total quality management (TQM) has different aspects, one of its main dimension is its tools, such as quality costing method, benchmarking, 7 old quality tools, and even ISO 9000 [13]. However, the quality of the products and services should be measurable in order to quantify the benefits of TQM implementation has been achieved by firm. Although there are numerous tools for measuring quality performance, the "cost of quality," or "quality costs," is the best indicator for this aim [5]. Crosby [2] specified the cost of quality as the price of "conformance" and "non-conformance, where the price of conformance is that which is needed to ensure things turn out right, and the price of "non-conformance" is the expense incurred in doing things wrong. This concept is more readily understood by the manufacturing sector because of the need to comply with specifications and standards set by the company or customers.

Also, This method performs as the most significant tool in measuring, monitoring, controlling and decision making quality activities in a firm which aims on business excellence [17]. In addition, Some influential TQM gurus advocated and emphasized on usefulness of employing this method in TQM implementation as an important indicator, which can reflect the performance of TQM in the organizations [12]. Many models of quality cost analysis have been developed since the inception of this concept by Joseph Juran. Subsequently, the classical PAF model was introduced by Feigenbaum [4], which distinguishes quality costs into Prevention-Appraisal-Failure categories [17], and likewise Philip Crosby [2] popularized the cost of quality concept. According to Omachonu and Ross [16], the most important factor to improve the competitiveness of any organization is to control and reduce quality costs, and many studies shows most companies do not consider this technique as influential tool to improve quality, the reason is $90 \%$ of quality cost is hidden, and by applying quality costing method, $100 \%$ or real cost of quality can be appeared. Nevertheless, those companies that use quality costs as an indicator are very competitive and successful in the market, reducing rework costs, and they can effectively improve their product or service quality.

Similarly, the literature review indicated that quality costing method as an important quality management tool is not applied in most quality management programs [11]. Also, the evidence indicated that organizations used a quality costing method were successful in reducing quality costs and improving quality for their customers [17]. Furthermore, the formulation, which mostly used in performing quality costing method by the organizations is the classical prevention-appraisal-failure (P-A-F) framework that developed

\footnotetext{
Neyestani B. (2017, March). "Quality Costing Technique: An Appropriate Financial Indicator for Reducing Costs and Improving Quality in the Organizations." https://doi.org/10.5281/zenodo.375973
} 
by aforementioned TQM gurus [12]. Therefore, to understand quality costs concept, its main elements and how it can detect the non-value added expenses with the aim of saving money and improving quality performance within the organizations, this paper was reviewed literature and discussed regarding the mechanism of this tool of total quality management.

\section{QUALITY COSTS CONCEPT AND ITS MAIN ELEMENTS}

Quality costing technique has become as one of the most "effective management tool" for collecting and "measuring" the expenses in maintaining quality in a production process and also identifies the non-value added expenses [17]. There has been a huge change in the concept of quality costs. In 1990s, the cost of quality was perceived as scrap cost, warranty cost, and running the quality assurance department cost where the management of the most companies thought that the quality improvement activities can cause increase production expenses without increasing profit. Juran [6], one of the world's leading quality theorists, has been advocating the analysis of the cost of poor quality (quality-related costs). He classified the quality cost in his quality cost model (Juran's quality triangle) as conformance and nonconformance cost, where conformance cost refers to improving quality, and non-conformance cost refers to poor quality. Juran's quality triangle is included two axises that are time on the horizontal axis and cost of poor quality on the vertical axis, he also justified that quality cost or "non-quality" as one of this graph is the best parameter to assess quality improvement into the organization [11].

After Juran, Feigenbaum [4] built on Juran's quality costs and categorized conformance cost into three main categories; prevention costs, appraisal costs and failure costs (internal and external failure costs). He believed that the quality costs on average amount to between 25 to $30 \%$ of annual sales. This is three to four times the average profit margin. Scrap and rework account for a significant part of these costs of "non-conformance". However, Crosby [2] was the first grue introduced quality cost in his book "Quality Is Free". He justified that "quality is measured by the costs of quality which is the expense of non-conformance as the cost of doing things wrong". Crosby and Juran emphasized on the role quality cost as "the primary management tools", in order to ensure that the quality improvement has been happening through the implementation of quality management program/s [5], [15]. In addition, Crosby [2] stressed that quality costs directly impacts the overall financial goal of a company, even a small reduction in cost of quality may boost the return on assets of a company by a significant amount. According to Kerzner [7], to verify that a product or service meets the customer's requirements requires the measurement of the costs of quality There are several reasons why the cost of quality should be explicitly considered in an organization [8], as follows:

Neyestani B. (2017, March). "Quality Costing Technique: An Appropriate Financial Indicator for Reducing Costs and Improving Quality in the Organizations." https://doi.org/10.5281/zenodo.375973 
1. The increase in the cost of quality because of the increase in the complexity of manufactured products associated with advances in technology

2. Increasing awareness of life-cycle costs, including maintenance, spare parts, and the cost of field failures

3. Quality management members can most effectively communicate quality issues in a way that management understands.

In the majority of the organizations, quality costs can be often between "10 to 30 percent of sales", or "25 to 40 percent of operating expenses". Some of these costs are visible, some of them are hidden [15]. While Juran [6] believed that Quality costs are the costs associated with preventing, finding, and correcting defective work. These costs are huge, running at $20 \%$ - $40 \%$ of sales. Consequently, the companies should not withhold to spend money for prevention costs, the reason is much less costly to prevent a defect than to correct one. The relationship between these costs is reflected in the 1-10-100 rule demonstrated in Figure 1, one dollar spent on prevention will save $\$ 10$ on appraisal and $\$ 100$ on failure costs [16]. Thus. the adoption of quality costs can help the firms to survive in the market, reduce rework costs, and improve the quality of products or services more than those companies do not use this method [17].

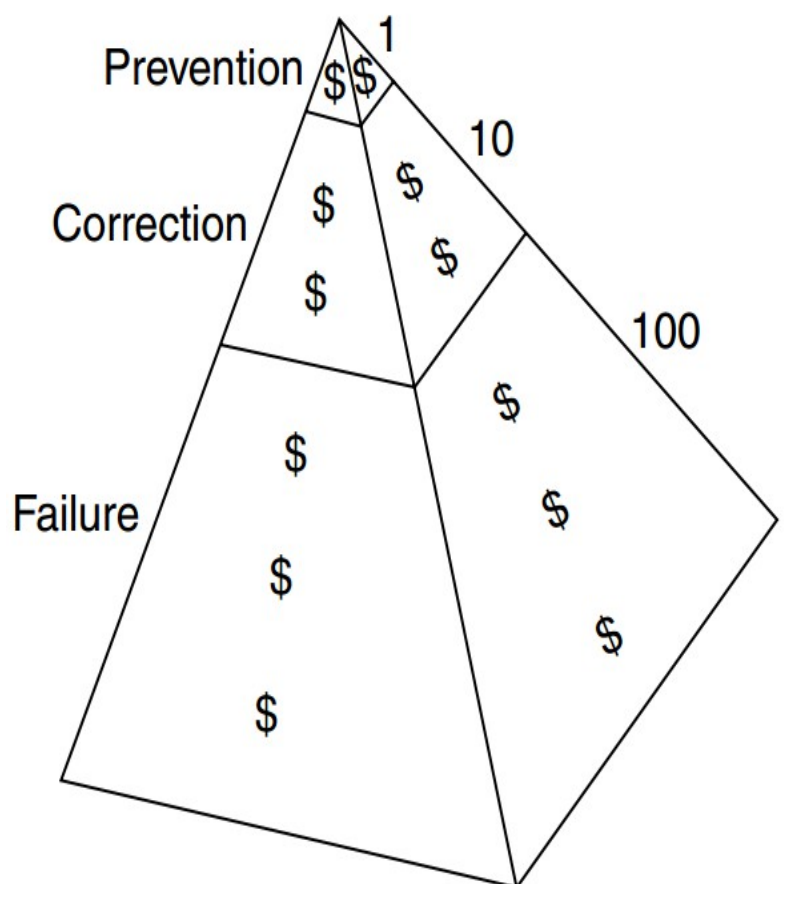

Figure 1: 1 1-10-100 Rule [16]

Neyestani B. (2017, March). "Quality Costing Technique: An Appropriate Financial Indicator for Reducing Costs and Improving Quality in the Organizations." https://doi.org/10.5281/zenodo.375973 
Nowadays, the most commonly used concept related to the quality costs are into prevention, appraisal, internal failure, and external failure costs. This typology is often referred to as the PAF (prevention, appraisal, and failure) [1]. However, the quality costs can be categorized into the four main groups, which are namely:

1) Prevention costs: These expenses related to costs of design and manufacturing that are directed toward the prevention of nonconformance and defect, and to meet customer's requirements [7], [1]. According to Juran [6], the prevention costs can be classified as Quality planning; New-products review; Process planning; Process control; Quality audits, and; Training; [14], [11], [7].

2) Appraisal costs: Those costs are included the expenses of measuring, evaluating, or auditing products of product or process (supplier's and customer's evaluation of purchased materials, processes, intermediates, products and services), to make sure the products or services are conformance with the specified requirements, standards, and the requirements of the customer in general. Appraisal costs are included [14]. Verification; Quality audits; Inspection equipment, and; Vendor rating [11];

3) Internal failure costs: These costs happen when the outcome of product or service process cannot meet designed quality standards and the requirement of customer, and this failure is found before transfer and delivery to the customer. These costs are Included in this area are Scrap; Rework; Repair; downtime; defect evaluation; evaluation of scrap, and; Corrective actions for these internal failures [7], [11] and;

4) External failure costs: These expenses generate when products or services cannot satisfy customer or specified requirements but the defects could not be discovered till delivery to the customer [1]. These expenses are Customer returns and allowances; Repair and servicing; Warranty claims; Complaints, and; Bad impact on the reputation and image [8], [7], [11].

\section{QUALITY COSTING METHOD AND QUALITY MANAGEMENT PROGRAMS}

Omachonu,Ross [16] noted that the most important issue to improve the competitiveness of any organization is to control and reduce quality costs, and many studies indicated the majority of the companies do not consider this technique as a powerful tool to improve quality of the products and services. Interestingly, $90 \%$ of the quality cost is hidden, but $100 \%$ or real cost of quality can appear by quality cost analysis. As mentioned earlier, the

Neyestani B. (2017, March). "Quality Costing Technique: An Appropriate Financial Indicator for Reducing Costs and Improving Quality in the Organizations." https://doi.org/10.5281/zenodo.375973 
emphasis of Crosby [2] was to measure the quality cost as an effective tool for leading quality within the organizations. He asserted that the cost of quality is a methodology that assists the companies to identify potential cost savings when process improvements are positively done. Similarly, Oakland [14] stated that the quality costs are a true measure of the quality management effort. A competitive product or service based on a balance between quality and cost factors is the principal goal of responsible management and may be aided by a competent analysis of the costs of quality. The analysis of quality-related costs is a significant management tool, which indicates the results of quality management program/s:

1. A method of assessing the effectiveness of quality management.

2. A means of determining problem areas, opportunities, savings, and action priorities during quality activities.

Juran [6] drew a graph to demonstrate how quality program/s can use the quality costing method in improving the quality of the products or services. This graph is included two axises that are time on the horizontal axis and cost of poor quality on the vertical axis, Juran stated that quality cost or "nonquality" is the best parameter to evaluate quality improvement into the organization. As shown in Figure 2, the minimum level of total quality costs can be obtained, when the quality of conformance is 100 percent (perfection). In other words, this tool can inform properly organization's management, in order to indicate how much the organization was successful to achieve organizational goals, which are quality improvement and cost reduction during quality management procedure [11].

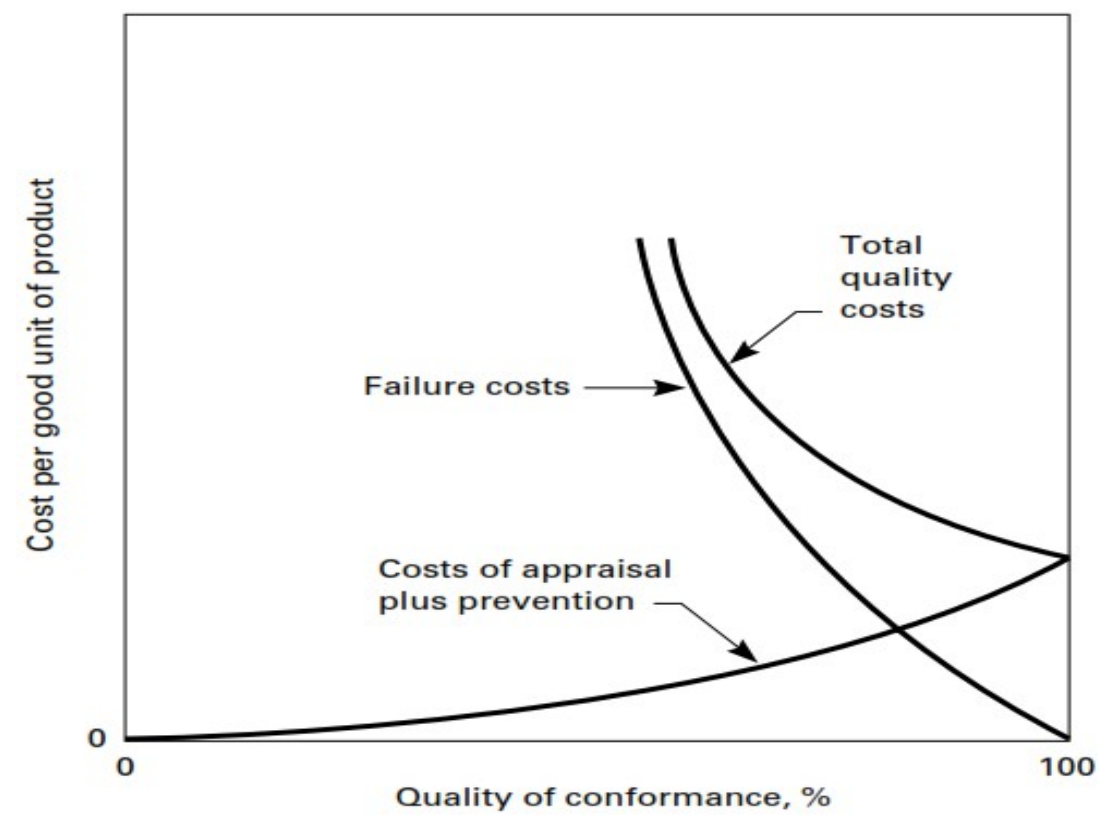

Figure 2: Model for optimum quality costs juran [6 p. 8.22]

\footnotetext{
Neyestani B. (2017, March). "Quality Costing Technique: An Appropriate Financial Indicator for Reducing Costs and Improving Quality in the Organizations." https://doi.org/10.5281/zenodo.375973
} 
Furthermore, Deming [3] believed that the reduction of non-conformance expenses (Quality costs) is a good evidence to prove that the company has an appropriate quality system (Quality chain) to produce products or services with high level of quality, as can be seen in Figure 3.

\begin{tabular}{|l} 
Improve \\
quality $\longrightarrow \begin{array}{c}\text { Costs decrease } \\
\text { because of less } \\
\text { rework, fewer } \\
\text { mistakes, fewer } \\
\text { delays, snags, } \\
\text { better use of } \\
\text { machine, time and } \\
\text { materials. }\end{array} \rightarrow \begin{array}{c}\text { Productivity } \\
\text { improves }\end{array} \rightarrow \begin{array}{c}\text { Capture the } \\
\text { market with } \\
\text { better } \\
\text { quality and } \\
\text { lower price }\end{array}$
\end{tabular}$\quad \begin{gathered}\text { Stay in } \\
\text { business }\end{gathered}$

Figure 3: Impact of an effective quality Management programs on reducing non-conformance expenses [3]

However, Juran [6] and Crosby [2] both believed that companies should apply quality costs as the primary quality measurement tool during the implementation of TQM for making sure the quality improvement has been happening [5], [15]. Oakland [11, p. 107] explained that the prevention costs effective indicator to reflect the costs have spent for design, implementation and maintenance of the "quality management system".

Similarly, Feigenbaum [4] asserted that the appraisal costs are cost related with maintaining the quality levels of the company, which can show the condition and level of quality management performance into the organization. $\mathrm{He}$ also believed that appraisal activities are commonly found in companies with high costs of non-conformance, and are present because the system produces so many errors. These unnecessary costs can be eliminated by identifying the causes of non-conformance and failure through the implementation of prevention activities, which is an important aspect of quality management program/s [11], [17]. As presented in Figure 4, quality costing method is an effective tool to indicate and lead the quality management program/s such as total quality management system. Prevention costs are expected to actually rise as more time is spent in prevention activities throughout the organization. As processes improve over the long run appraisal costs will go down as the need to inspect in quality decreases. The biggest savings will come from the internal failure areas of rework, scrap, reengineering, redo, and so on [7], [8].

Neyestani B. (2017, March). "Quality Costing Technique: An Appropriate Financial Indicator for Reducing Costs and Improving Quality in the Organizations." https://doi.org/10.5281/zenodo.375973 


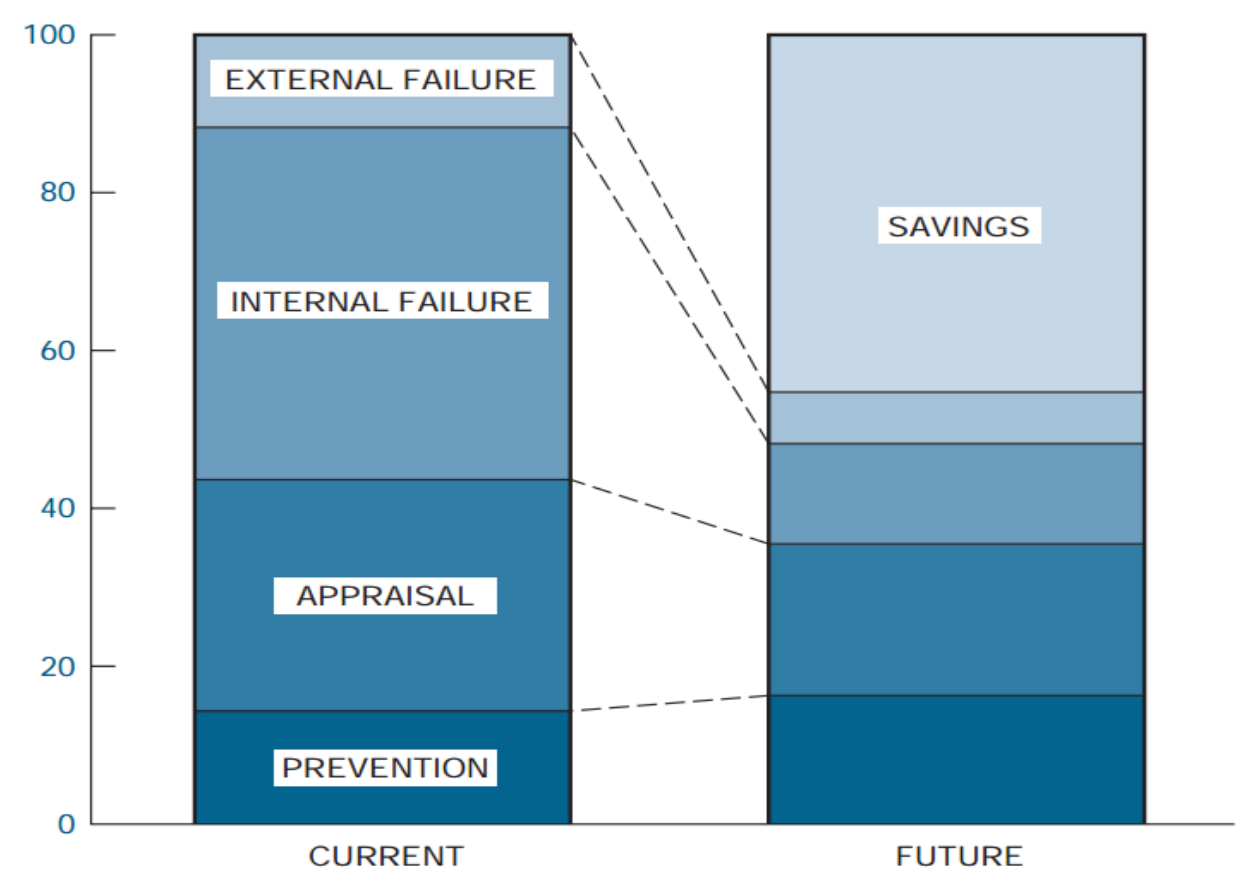

Figure 4: Integrated quality costing method with TQM as a strategic management tool and an indicator for measuring and ensuring to achieve performance excellence during TQM implementation [7]

\section{CONCLUSION}

Numerous companies promote quality as the central customer value and consider it to be a vital element for obtaining competitiveness. Any serious effort to promote quality should take into account the costs associated with achieving quality since the objective of continuous improvement programs is not only to meet customer requirements, but also to do it at the lowest cost. This can only happen by reducing the costs related to the quality, and the reduction of these costs is only possible if they are distinguished and measured [11], [17]. Therefore, the adotion of the cost of quality should be an important criterion for decision making by the managers. Furthermore, cost reduction is an approach within an organization towards improving quality and controlling company expenses. Accordingly, all organizations should perform the quality management program/s with quality costing tool, in order to ensure doing all things properly under an effective quality system [2], [4], [11], [12]. In summary, quality costing method provides a good way for measuring the performance of quality system in the organization with the aim of ensuring the firm achieving successfully the benefits of quality program/s [6], and reducing the costs related to quality of the products or service, which is extremely important to satisfying customers.

\section{References}

1. Campanella, J. (1990), Principles of Quality Costs (2 ${ }^{\text {nd }}$ ed.), WI, Milwaukee: ASQ Quality Press.

Neyestani B. (2017, March). "Quality Costing Technique: An Appropriate Financial Indicator for Reducing Costs and Improving Quality in the Organizations." https://doi.org/10.5281/zenodo.375973 
2. Crosby, P.B. (1979). Quality Is Free: The Art of Making Quality Certain. New York: McGraw-Hill.

3. Deming, W. E. (1986) Out of the Crisis: Quality, Productivity, and Competitive Position Cambridge, MA: Cambridge University Press.

4. Feigenbaum, A. (1991). Total Quality Control ( $3^{\text {rd }}$ ed.). New York: McGrawHill.

5. Forbes, L H. \& Ahmed S. M. (2011). Modern construction : lean project delivery and integrated practices. Boca Raton, Fly: Taylor and Francis Group.

6. Juran, M., and Godfrey, A. (1998). Juran's quality handbook ( $5^{\text {th }}$ ed.). Washington, DC: McGraw-Hill Companies, Inc.

7. Kerzner, H. (2009). Project Management: A Systems Approach to Planning, Scheduling, and Controlling ( $10^{\text {th }}$ ed.). Hoboken, New Jersey: John Wiley \& Sons, Inc.

8. Montgomery, D. C. (2009). Introduction to Statistical Quality Control (6 ${ }^{\text {th }}$ ed.). Danvers, MA: John Wiley \& Sons, Inc.

9. Neyestani, B., \& Juanzon, J. B. P. (2016). "Identification of A Set of Appropriate Critical Success Factors (CSFs) for Successful TQM Implementation in Construction, and Other Industries," International Journal of Advanced Research, 4(11), pp. 1581-1591. http://dx.doi.org/10.21474/IJAR01/2248

10. Neyestani, B., \& Juanzon, J. B. P. (2016). "Developing an Appropriate Performance Measurement Framework for Total Quality Management (TQM) in Construction and Other Industries. IRA-International Journal of Technology \& Engineering, 5(2), pp. 32-44. http://dx.doi.org/10.21013/jte.v5.n2.p2

11. Neyestani B., \& Juanzon, J. B. P. (2017). "Impact of ISO 9001 Standard on the Quality Costs of Construction Projects in the Philippines." Proceedings of 2017 Manila International Conference on "Trends in Engineering and Technology" (MTET-17), pp. 60-65, Jan. 23-24, 2017 Manila, Philippines. (ISBN: 978-93-84468-98-9). http://doi.org/10.17758/URUAE.AE0117504

12. Neyestani, B. (2017). "Principles and Contributions of Total Quality Mangement (TQM) Gurus on Business Quality Improvement.", 2017, February. https://doi.org/10.5281/zenodo.345428

13. Neyestani B., \& Juanzon, J. B. P. (2017). ISO 9001 Standard and Organization's Performance: A Literature Review. Int. J. Adv. Multidiscip. Res. 4(2): pp. 6-13. http://dx.doi.org/10.22192/ijamr.2017.04.02.002

14. Oakland, J. S. (2003). Total Quality Management: text with cases ( $3^{\text {rd }}$ ed.). Jordan Hill, Oxford, UK: Butterworth-Heinemann, an imprint of Elsevier.

15. Oberlender, G. D. (2000). Project Management for Engineering and Construction ( $2^{\text {nd }}$ ed.). New York, USA: McGraw-Hill Companies, Inc.

16. Omachonu, V. K. \& Ross, J. E. (2004). Principles of total quality ( $3^{\text {rd }}$ ed.). Boca Raton, Florida: Taylor \& Francis.

17. Sailja, A., Basak, P. C., \& Viswanadhan, K. G. (2015). "HIDDEN COST OF QUALITY: MEASURMENT \& ANALYSIS," International Journal of Managing Value and Supply Chains., vol. 6, no. 2, pp. 13-25. http://doi.org/10.5121/ijmvsc. 2015.6202

Neyestani B. (2017, March). "Quality Costing Technique: An Appropriate Financial Indicator for Reducing Costs and Improving Quality in the Organizations." https://doi.org/10.5281/zenodo.375973 